\title{
Validation of an Instrument to guide Nursing Staffing in Obstetric Rooming in
}

\author{
Validação de Instrumento para fundamentar dimensionamento de Profissionais de Enfermagem em Alojamento Conjunto
}

Validación de Instrumento para fundamentar dimensionamiento de Profesionales de Enfermería em Alojamiento Conjunto

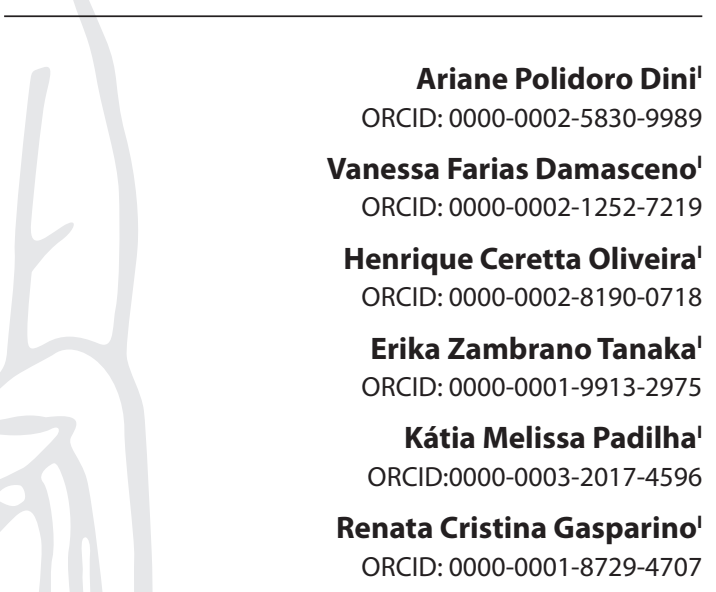

'Universidade Estadual de Campinas. Campinas, São Paulo, Brazil.

How to cite this article:

Dini AP, Damasceno VF, Oliveira HC, Tanaka EZ, Padilha KM, Gasparino RC. Validation of an Instrument to guide Nursing Staffing in Obstetric Rooming in Rev Bras Enferm. 2020;73(4):e20190159. doi: http://dx.doi.org/10.1590/0034-7167-2019-0159

Corresponding author: Ariane Polidoro Dini E-mail: adini@unicamp.br

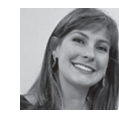

EDITOR IN CHIEF: Antonio José de Almeida Filho ASSOCIATE EDITOR: Alexandre Balsanelli

Submission: 09-08-2019

Approval: 10-12-2019

\section{ABSTRACT}

Objectives: to construct and validate an instrument for the classification of mother-baby binomials that subsidizes personnel Staffing in in-rooming units. Method: methodological study. The construction was based on theoretical and legal references. Content validity was performed by experts through the content validity index measurement. Then, the instrument was applied to a sample of 122 binomials, and exploratory factor analysis was performed using the principal components analysis. Results: the instrument consisted of seven care indicators: Birth route; Maternal morbidity; Neonatal morbidity; Breastfeeding; Social aggravating factors; Care guidance; and interaction and bonding. All with content validity index of 1 . The construct was composed of 3 domains, with Cronbach's alpha of $0.62,0.85$ and 0.89 . Conclusions: the classification instrument of mother-baby binomials allows the classification of mother-baby binomials and may support personnel Staffing in in-rooming units.

Descriptors: Rooming-in Care; Validation Studies; Workforce; Hospital Organization and Administration; Obstetric Nursing.

\section{RESUMO}

Objetivos: construir e validar um instrumento para classificação de binômios puérpera-neonato que subsidie o dimensionamento de pessoal em unidades de alojamento conjunto. Métodos: estudo metodológico. A construção foi embasada em referenciais teóricos e legais. A validade de conteúdo foi realizada por expertos por meio de mensuração do índice de validade de conteúdo. Em seguida, o instrumento foi aplicado em uma amostra de 122 binômios, e foi realizada análise fatorial exploratória pelo método de componentes principais. Resultados: o instrumento ficou constituído por sete indicadores de cuidado: Via de parto; Morbidade materna; Morbidade neonatal; Aleitamento; Agravantes sociais; Orientação de cuidados; e Interação e vínculo. Todos com índice de validade de conteúdo iguais a 1 . O constructo foi composto por 3 domínios, com Alfa de Cronbach de 0,62, 0,85 e 0,89. Conclusões: o instrumento para a classificação de binômios puérpera-neonato permite a classificação de binômios puérpera-neonato e poderá embasar o dimensionamento de pessoal em alojamento conjunto.

Descritores: Alojamento Conjunto; Estudos de Validação; Dimensionamento de Pessoal; Organização e Administração; Enfermagem Obstétrica.

\section{RESUMEN}

Objetivos: elaborar y validar un instrumento para clasificación de binomios puerperio neonatal que subsidie el dimensionamiento de personal en unidades de alojamiento conjunto. Métodos: estudio metodológico. La construcción ha sido basada en referencias teóricas y legales. La validez de contenido ha sido realizada por expertos por medio de medición del índice de validez de contenido. Luego, el instrumento ha sido aplicado en una muestra de 122 binomios, y ha sido realizado análisis factorial exploratoria por el método de componentes principales. Resultados: el instrumento ha quedó constituido por siete indicadores de cuidado: Vía de parto; Morbilidad materna; Morbilidad neonatal; Amamantamiento; Agravantes sociales; Orientación de cuidados; e Interacción y vínculo. Todos con índice de validez de contenido iguales a 1. El constructo ha sido compuesto por 3 dominios, con Alfa de Cronbach de 0,62, 0,85 y 0,89 . Conclusiones: el instrumento para la clasificación de binomios puerperio neonatal permite la clasificación de binomios puerperio neonatal y podrá basarse el dimensionamiento de personal en alojamiento conjunto.

Descriptores: Alojamiento Conjunto; Estudios de Validación; Dimensionamiento de Personal; Organización y Administración; Enfermería Obstétrica. 


\section{INTRODUCTION}

The use of Patient Classification Systems (PCS) was introduced in the 20th century to characterize inpatient units, as it was found that only knowing the number of beds, the occupation percentage, and the patients classification by medical diagnosis, age, and gender did not distinguish care needs ${ }^{(1)}$. The fundamental purpose of patient classification is to generate information about patient care needs, thus supporting the management and planning of human and material resources to promote safe and quality care $\mathrm{c}^{(2-5)}$.

PCS is composed of some essential features: an instrument to predict nursing care needs; standardization of the number of hours in each care category; a database to relate care needs to resources allocation; and a method for monitoring the reliability of the patient classification system over time ${ }^{(2-5)}$.

In Brazil, the number of assistance hours for each care category was standardized by the Federal Nursing Council(6)

This study is justified by the absence of instruments that classify the mother-baby binomial in obstetric rooming-in. Regularly, the classification is performed by instruments that only allow the evaluation of the postpartum woman as an adult patient, disregarding the specificities of puerperal or newborn care and the demand for care guidelines intrinsic to the period.

Obstetric rooming-in is part of a hospital system in which newborn and mother stay together 24 hours a day in the same environment from birth to discharge. Such a system strengthens the affective bonds between mother and child, enables nursing to provide all care, as well as guide and encourage exclusive breastfeeding ${ }^{(7-8)}$.

Considering that the nursing staff in rooming-in provides integral care throughout the binomial hospitalization, it can be recognized the importance of a classification instrument that addresses the specificities of nursing care for puerperal and neonates to instrumentalize daily operational planning and human and material resource management.

\section{OBJECTIVES}

To construct and validate an instrument to classify the motherbaby binomials in nursing accommodation into nursing care categories.

\section{METHODS}

\section{Ethical aspects}

The study was approved by the Research Ethics Committee under opinion 2.167.085.

\section{Study Design, location, and period}

A Methodological study conducted in a tertiary and quaternary hospital that provides care to women and newborns.

The study occurred in three stages from September 2016 to December 2017:

1. Instrument construction from September 2016 to June 2017;

2. Content validation with participation of experts from August to October 2017;
3. Application of the instrument to a sample of 122 binomials to assess construct validity and reliability from October to December 2017.

\section{Inclusion and exclusion criteria}

To participate in the study as expert nurses for assessing the instrument and validating content, the following inclusion criteria were established: having care assistance or managerial experience in obstetric rooming-in for more than three years, or being researchers involved in validation studies. The exclusion criteria were: not expressing interest or understanding to judge the content of the binomial classification instrument; disagree with the signing of the Informed Consent Form of the research protocol approved by REC.

The data collection procedure for the instrument pretesting was performed by one of the authors of the study, who has been assisting at the collection locality for four years. Each binomial was classified only once. There was no binomial selection, and all were considered eligible for classification of their dependence on care from the nursing perspective.

\section{Study Protocol}

The construction of an initial version of the Binomial Classification Instrument $(\mathrm{BCl})$ was based on instrument construction and validation studies ${ }^{(9-11)}$, a legal framework for nursing staffing ${ }^{(6)}$, and obstetric rooming-in or immediate postnatal and puerperium period references ${ }^{(7-8,12-15)}$.

After the literature review, it was agreed that the construction would follow the structure of previously validated instruments ${ }^{(9-11)}$, with indicators scored from 1 to 4 and whose sum of all validated indicators was associated to a classification scale of care categories.

It was also agreed that the instrument's classification scale would consider three care categories, according to the current legislation ${ }^{(6)}$ : intermediate care, high dependency care and semiintensive care. The total possible points of the scale were equally distributed among the three categories of care, according to the patient classification instruments adopted in the Brazilian culture and indicated by legislation ${ }^{(6)}$.

Three three-hour meetings were held between the first two authors to compose a "zero" version of the instrument for validation.

Content validation was performed using the Delphi technique in two rounds to reach a consensus from the expert panel ${ }^{(16)}$. The advantages of this technique were the application of printed questionnaires, the absence of physical assembly, and impersonal answers interpretation ${ }^{(16)}$. The identification of expert nurses occurred for the convenience of the researchers. When identifying nurses who met the inclusion criteria, they were personally invited and received the printed questionnaire and the consent form for the assessment.

First, it was evaluated the dimensionality of the instrument, its composition and indicators formatting ${ }^{(10,17)}$. For this, the experts were asked to consider everything that surrounds the nursing care demand in obstetric rooming-in, and thus direct or indirect care time and care complexity. And, to evaluate each of the proposed indicators, the following questions were raised: "Is this indicator important in assessing nursing care demand? Is the score increasingly organized according to nursing care demand? 
Do you agree with this indicator? Suggest modifications." After judging all indicators, it was asked: "Do you suggest deleting or including any indicator?".

Modifications were made in the instrument composition and wording, according to the experts' suggestions. Then, followed the second evaluation step, in which, besides the questions about each indicator and its score, its clarity and relevance were evaluated to assess the Content Validity Index $(\mathrm{CVI})^{(9,17)}$.

\section{Results analysis and statistics}

In the CVI assessment, the experts assigned each instrument indicator one of four options: "1) Not relevant or not clear to assess nursing care demand; or 2) Needs major overhaul to be relevant or clear in assessing nursing care demand; or 3) Needs a minor review to be relevant or clear in assessing nursing care demand; or 4) Relevant and representative in the assessment of nursing care demand."To calculate the CVI of each indicator, we considered the total number of options " 3 " or " 4 " assigned by the judges, divided by the total number of responses, so that indicators with CVI higher than 0.90 were considered valid ${ }^{(10,17)}$.

In the classification of the 122 binomials, each care indicator score was recorded in the best-represented option of the puerpera's or newborn's condition. Results were sequentially tabulated in an electronic spreadsheet to assess construct validity and reliability.

Exploratory factor analysis (EFA) allowed us to explore the construct by the relationship between the set of indicators and identify correlation patterns. This technique can be used in the earliest stages of instrument construction and validation. To verify the fit of the data to the EFA, the Kaiser-Meyer-Olkin Index (KMO) was calculated and Bartlett's sphericity test was applied. The values considered adequate for performing the EFA were $\mathrm{KMO}>0.5$ and a statistically significant Bartlett sphericity test, i.e. $p$ value $<0.05^{(11,17)}$.

Once the adequacy of the data to the AFE was verified, the factors extraction continued, that is, the instrument domains or constructs. The factors extracted were the ones with eigenvalues greater than 1 and that together, represented a value greater than $60 \%$ of the total explained variance (LV), a condition for the instrument construct ${ }^{(11,17)}$.

After factor extraction, the communalities and factor loadings of the instrument indicators in each instrument domain were analyzed in the factorial model. The commonalities represent the ratio of an indicator's LV in its domain and must be higher than $0.6^{(17)}$. The factor loadings represent the correlation of the indicator with its domain in the instrument, and values greater than 0.70 indicate a well-defined structure ${ }^{(17)}$.

Statistical Package for Social Sciences ${ }^{\circledast}$ (SPSS) version 22 software was used and AFE was performed using the Varimax rotation principal component method.

Then, the reliability of the instrument regarding the internal consistency aspect was evaluated by Cronbach's alpha, whose values between 0.70 and 0.95 are desirable ${ }^{(18)}$.

\section{RESULTS}

After studying the literature, 12 nursing care demand in obstetric rooming-in indicators were constructed: Maternal age; Birth route; Maternal comorbidity; Capurro; Breastfeeding; Breast-latch and sucking; Newborn glycemia; Assistance and support; Social aggravating factors; Phototherapy; Complications in the first four hours of life; and NB Care.

In the first stage of the Delphi technique, 13 experts were invited and effectively participated, being 3 nurse managers, 8 assistant nurses and 2 researchers. Four experts suggested a ten care indicators grouping, and one suggested excluding "maternal age" from the care demand assessment.

A second version of the binomial classification instrument with ten care indicators was consolidated: Maternal age; Birth route; Maternal morbidity and complications; Gestational age; Neonatal morbidity and complications; Breast-latch and sucking, Breastfeeding; Social aggravating factors; Care education and guidance / discharge preparation; Interaction and bonding.

In the second stage of the Delphi technique, 13 questionnaires were delivered to the same experts who participated in the first stage, however 1 expert did not participate due to being on vacation. This questionnaire was given to a teacher specialist in obstetrics and gynecology and rooming-in assistance so that she joined the group of experts participating in the study.

After 3 weeks, only 10 out of 13 questionnaires returned with the assessment. Thus, the participants experts in the second stage were: two nurse managers, five care nurses and three researchers.

In this second stage, only the indicator "Maternal age" was pointed by an expert as "1) Not Relevant". The other nine indicators were assessed as "3) Needs a minor review to be relevant or clear in assessing nursing care demand". Thus, the CVI of the maternal age indicator was 0.9 and of the other proposed indicators was 1 . Adjustments were made to improve the clarity of the content of the indicators according to the experts' suggestions, and the instrument was applied for two months in an obstetric rooming-in setting.

As a result of the application, 107 binomials (88\%) were classified as intermediate nursing care and 15 binomials (12\%) were classified as high dependency care, and none of the binomials were classified as semi-intensive care.

The data resulting from the application of the instrument fit the EFA with $p<0.0001$ for Bartlett's sphericity test; and $\mathrm{KMO}=0.62$.

The EFA allowed the identification of three domains of the instrument with $81.28 \%$ of the LV. The first domain presented $40.36 \%$ of LV and was identified as "Technical Assistance Dimension" because it grouped the indicators: "Birth Route", "Maternal morbidity and complications", "Neonatal morbidity and complications". The second domain accounted for $25.56 \%$ of LV and was named "Maternal Support Network" because it grouped the indicators "Breastfeeding" and "Social Aggravating factors". The third domain, responsible for $15.36 \%$ of the LV, was named "discharge preparation" and grouped the indicators "Care education and guidance" and "Interaction and bonding".

Three indicators did not fit the construct of any of the three domains, so they were excluded from the instrument:"Maternal age", "Gestational age" and "Breast-latch and sucking".

Thus, the Rooming-in Binomial Classification Instrument (RIBCI) was composed of 7 care indicators and is fully presented in Chart 1. 
Chart 1 - Rooming-in Binomial Classification Instrument, Campinas, São Paulo, Brazil, 2018

Instruction: Evaluate, at the same time, the puerperal and the newborn according to the seven care indicators and choose the situation that best represents the care situation. Then sum the points of each indicator and compare with the binomial classification scale.

\section{(I)Birth Route}

1 - Vaginal delivery without use of surgical instruments (forceps);

2 - Vaginal delivery using surgical instruments or with laceration or episiotomy;

3 - Cesarean section surgery;

4 - Caesarean section surgery with tubal ligation.

(II) Maternal morbidity and complications

1 - Puerperal woman without comorbidities or complications;

2 - Puerperal woman with comorbidities or complications that indicate the need for nursing care every 6 hours;

3 - Puerperal woman with comorbidities or complications that indicate the need for nursing care every 4 hours;

4 - Puerperal woman with comorbidities or complications that indicate the need for nursing care every or monitoring at 2 hours intervals or less.

\section{(II) Maternal morbidity and complications}

1 - Puerperal woman without comorbidities or complications;

2 - Puerperal woman with comorbidities or complications that indicate the need for nursing care every 6 hours;

3 - Puerperal woman with comorbidities or complications that indicate the need for nursing care every 4 hours;

4 - Puerperal woman with comorbidities or complications that indicate the need for nursing care every or monitoring at 2 hours intervals or less.

\section{(IV) Breastfeeding}

1 - Exclusive breastfeeding;

2 - Breastfeeding and cup/bottle-feeding supplementation without nursing assistance;

3 - Breastfeeding and cup / bottle-feeding supplementation with nursing assistance;

4 -Relactation.

\section{(V) Social aggravating factors}

1 - Puerperal woman and neonate have unrestricted family support, with no history of social aggravation occurrences;

2 - Puerperal woman and neonate do not have family support, but there is no history of social aggravation occurrences;

3 - Puerperal woman and neonate do not have family support and there is a history of occurrences of social aggravating factors such as prenatal self-neglect or judicial process;

4 - Puerperal woman with a history of chemical dependency AND / OR living in a shelter or being homeless AND / OR case history for custody of previous children or current child.

\section{(VI) Care education and guidance}

1 - Independent puerperal woman, received guidance from nursing and show autonomy to provide the newborn with care;

2 - Puerperal woman received nursing guidance, but still needs direct supervision to provide the newborn with care;

3 - Puerperal woman received nursing guidance, but needs constant and recurrent nursing assistance to provide the newborn with care; 4 - Puerperal woman has not received or refuses to comply with the nursing guidelines regarding the performance of newborn care AND / $\mathrm{OR}$ is unable to provide the newborn with them.

\section{(VII) Interaction and Bonding}

1 - Binomial with good interaction / bonding;

2 - Binomial with little interaction / bonding;

3 - Puerperal woman needs incentive to bond and interact with neonate;

4 - Puerperal woman without enough interaction/bonding with neonate, even after incentive.

\section{Binomial Classification Scale}

7 to 13 points = Intermediate care;

14 to 20 points $=$ High dependency care;

21 to 28 points $=$ Semi-intensive care.

\section{$\mathrm{RIBCI}$ construct validity and internal consistency}

The assessment results regarding the commonality, factor loadings, and Cronbach's alpha of each indicator in their respective domains are presented in Table 1.

Table 1 - Construct Validity and Internal Consistency of the Obstetric Roomingin Binomial Classification Instrument, Campinas, São Paulo, Brazil, 2018

\begin{tabular}{lccc}
\hline Domain / Indicators & Commonality & $\begin{array}{c}\text { Factor } \\
\text { loading }\end{array}$ & $\begin{array}{c}\text { Cronbach's } \\
\text { Alpha }\end{array}$ \\
\hline $\begin{array}{l}\text { Technical Assistance Dimension } \\
\text { Birth Route }\end{array}$ & & & 0.62 \\
$\quad$ Maternal morbidity/complications & 0.71 & 0.94 & \\
$\quad$ Neonatal morbidity / complications & 0.90 & 0.87 & \\
Maternal support dimension & & & \\
$\quad$ Breastfeeding & 0.82 & 0.94 & \\
$\quad$ Social aggravating factors & 0.67 & 0.94 & \\
$\begin{array}{l}\text { Discharge support dimension } \\
\quad \text { Care education and guidance }\end{array}$ & 0.77 & 0.89 & 0.89 \\
$\quad$ Interaction and Bonding & 0.91 & 0.78 & \\
\hline
\end{tabular}

\section{DISCUSSION}

The construction of the binomial classification instrument followed a previously validated patient classification instrument structure $^{(9)}$ and was motivated and based on legislation of the Federal Nursing Council, which establishes a minimum standard of nursing care hours per day in five care categories: 4 hours for minimum care, 6 hours for intermediate care, 10 hours for high dependence or semi-intensive care and 18 hours for intensive care ${ }^{(6)}$.

Due to the lack of instruments for classifying binomials (motherbaby) at the time of the legislation establishment, it was recommended that they were classified based on the intermediate care category ${ }^{(6)}$.

Thus, in the instrument construction, based on the literature review ${ }^{(3-9,12-14)}$ and in legislation related to the use of $\mathrm{PCS}^{(6)}$, it was decided not to include in the RIBCI the category of minimum care, as it is recognized that four hours of nursing care in one day are insufficient to meet the care demand of a mother-baby binomial in obstetric rooming-in.

Aligned with the care proposals of the Obstetric Roomingin, the category of intensive care was not included in the $\mathrm{RIBCl}$ construction either, since the severity and death risk of both the mother and the newborn should not be part of this accommodation. Therefore, not the binomial, but the patient who needs intensive care should be allocated to an obstetric or neonatal intensive care unit, with medical and nursing support that can provide them with safe care ${ }^{(7-8,12-14,19)}$.

Thus, the instrument proposal included the categories of intermediate care, high dependency care, and semi-intensive care, which will make the nursing staffing possible both numerically and in the percentage distribution of the nursing professionals total ${ }^{(6)}$.

The challenge of composing specific rooming-in care indicators was presented in the first stage of content validation, in which, even though the experts agreed on the relevance of the 12 proposed indicators, they suggested changes that motivated a careful review and fusion of indicators, resulting in a 10 indicators version. 
The review motivated by the experts took place in harmony with PCS frameworks ${ }^{(2-5)}$, in which it is stated that a PCl should not be a summation of nursing activities, but should be guided by the demand for care generated, which It is influenced both by patients' dependence on activities of daily living, complexity of care required, and by direct and indirect workload.

In the second stage of content validation, 9 out of the 10 indicators were unanimously considered relevant $(\mathrm{CVI}=1)$ and the indicator "Maternal age" was considered irrelevant by one of the experts $(\mathrm{CVI}=0.9)$.

An intermediate version of the instrument with 10 indicators was applied in 122 binomials to explore its construct. The sample exceeded ten cases per instrument item / indicator, because the higher the number of cases, the better the EFA technique, with greater possibility of parsimony and explanation of the instrument construct ${ }^{(16)}$.

The construct identified by the EFA was explained by three evaluation domains that include three major sources of nursing care in obstetric rooming-in: the "Technical Assistance Dimension", the "Maternity Support Network" domain and the "discharge preparation" domain. Together, the three domains presented $81.28 \%$ of $L V$, pointing to the validity of the construct ${ }^{(10,16)}$. However, three of the ten proposed indicators did not fit the extracted domains and needed to be excluded from the RIBCI composition.

The "Maternal Age" indicator, one of the three indicators excluded after EFA, had already been pointed out as irrelevant by one of the experts. The justification was the absence of evidence of the interference of the puerperal woman age in demand for nursing care, concerning the degree of dependence on care activities or better development of skills in newborn care. Thus, the EFA corroborated to the recommendation to exclude this indicator.

The indicators "Gestational age" and "Breast-latch and sucking" showed low application variability, justifying their non-adjustment to any of the domains identified by the EFA and their consequent exclusion from the RIBCI. In the case of "Gestational age", after the application of the instrument, it seemed obvious that this assessment would not be coherent, considering that the babies assigned to rooming-in are mature enough not to require semiintensive care. In specific cases of neonatal morbidity related to late preterm, the indicator "Neonatal morbidity and complications" will allow evaluating the nursing demand that results from this technical assistance.

Also, during the application of the instrument, it was found that the indicator "Breast-latch and sucking" was included in the indicator "Breastfeeding", which considers that, during effective breastfeeding, the correct newborn grip facilitates breastfeeding to become a pleasurable act, minimizing complications and motivating women who are breastfeeding with higher safety and satisfaction. ${ }^{(13,20-21)}$. The nursing care needed to support breastfeeding, and assist mother and newborn, whether due to the need for supplementation by cup or bottle, or by relactation, were provided for in the "Breastfeeding" indicator, as presented.

Among the indicators with validated construct, it is noteworthy that the indicator "Birth route" was constructed and considered relevant by the judges in the content validation. In the situation gradation, the cesarean section weights higher when compared to normal delivery. They consider that c- section affects the demand for nursing care after delivery, either for hygiene and comfort care needs or the administration of analgesics ${ }^{(21)}$.

The indicators "Maternal morbidity and complications" and "Neonatal morbidity and complications" refer to the interval required for nursing care, whether regarding the control of vital signs, glycemia, sample collection for laboratory tests, or pain management, dressing, supporting the most requesting or anxious puerperal women. That is, both indicators aim at preventing complications or reestablishing both mother and newborn health when there are risks inherent to the puerperal or neonatal period $^{(13-14)}$. It is noteworthy that monitoring and recording the vital signs of the puerperal woman and neonate should promote safety in the early identification of common complications when they are being transferred to the semi-intensive or Intensive treatment unit, or during the period they must stay in these units.

In the "Maternity support" domain, the "Social aggravating factors" indicator allows the evaluation of how the current and previous history of puerperal women can interfere in the demand for nursing care. The situations listed were suggested, in a complementary way, by the judges in the first stage of content validation, based on their experience and tacit knowledge. The evaluation of this indicator provides the nurse's performance in this postpartum period, subject to modifications in the family arrangement that may contribute to "improved family processes" or to act in the "risk for impaired maternity"; or also assist in coping with situational crises with "interrupted family processes" due to the transition that occurs in the period ${ }^{(20)}$.

The evaluation of the indicator "Care education and guidance/ discharge preparation" transcends its importance in the composition of the instrument within the classification in categories of care, but it is an indicator to be monitored on duty to the promotion of the quality and safety of the puerperal woman and the neonate. Its evaluation allows nursing professionals to create strategies to gain the mothers' trust in promoting breastfeeding, preventing early weaning ${ }^{(12-14,20)}$. Moreover, it is important that, when planning the health care of the puerperal woman, the professional considers all the information and life habits that the woman presents, as well as the knowledge, experiences, taboos, beliefs, habits, and cultural practices resulting from family living ${ }^{(12-14,20)}$.

The evaluation of the indicator "Interaction and bonding" was considered relevant by the experts due to the anxiety regarding the biological and family changes witnessed by the nursing team in the care and corroborates the identification of nursing diagnoses of the "risk for impaired bonding" in other studies ${ }^{(19,22)}$. However, in data collection, this indicator requires information from all stages of the nursing care systematization so that it can raise problems and propose interventions to achieve excellence in care practice.

The communalities between 0.72 and 0.90 for the technical assistance dimension, between 0.67 and 0.90 for the "Maternity support" dimension, and between 0.77 and 0.91 for the "Discharge support" dimension indicate the proportion of the variance of the indicators explained by the domains ${ }^{(18)}$.

The factor loading of the seven indicators between 0.78 and 0.94 indicates a good correlation between them and their respective domains, as well as demonstrate that the structure of the instrument is well defined ${ }^{(18)}$. 
The reliability of the RIBCI was indicated by the Cronbach's alpha values of 0.85 for "Maternity support network" and 0.89 for "Discharge preparation". The domain comprised of the indicators "Birth route", "Maternal morbidity and complications" and "Neonatal Morbidity and complications" presented Cronbach's alpha equal to 0.62 , which can be explained by the heterogeneity of the construct "Technical assistance dimension" and not by compromising the reliability of the scale $\mathrm{e}^{(19)}$.

In this study, the reliability of the RIBCI was evaluated only considering its internal consistency, so that the application of the instrument in other units of obstetric rooming-in should be performed to evaluate the reliability of the instrument in other realities.

Given the absence of binomials classified in the category of semi-intensive care, it is assumed that classifying binomials in this category will be unusual, which is due to rooming-in be a hospital care unit planned for the care of healthy puerperal Women and neonates ${ }^{(7-8,12-14)}$. However, it is identified as a limitation of the instrument the characteristic of not predicting deterioration of the clinical condition or the puerperal woman or the newborn. Thus, it is recommended to apply early warning signs instruments in complementarity to the application of $\mathrm{RIBCl}$ so that the health team recognizes and optimizes care actions in the face of alert situations or potentially urgent in the attendance of Puerperal women and Newborns ${ }^{(22-25)}$.

\section{Study Limitations}

The limitations refer to the absence of a specific validation study to conceive the categories of binomial care in rooming-in; and the validation procedure is restricted to only one hospital. No reliability test was performed between evaluators for instrument validation.
Therefore, the application of the $\mathrm{RIBCI}$ in other realities will allow the comparison of the results with those performed in other institutions and the confirmation of the construct by confirmatory factor analysis.

\section{Contributions to the field}

The fundamental contribution of this study to the advancement of scientific knowledge consists in the provision of a classification instrument for mother-baby binomials hospitalized in three categories of care that will enable the nurse staffing in obstetric rooming-in.

\section{CONCLUSIONS}

This study enabled the construction of a mother-baby binomial classification instrument in the categories of intermediate, high dependence and semi-intensive care, consisting of seven indicators distributed in three domains. The content validity of the instrument is adequate for having CVI greater than 0.9 for all indicators. The EFA made it possible to analyze the construct validity by demonstrating that the extracted factors, also called "domains", reached $81.28 \%$ of the explained variance. There is evidence of internal consistency of the $\mathrm{RIBCI}$ in relation to Cronbach's alpha values between 0.6 and 0.89 in the 3 domains of the instrument. Therefore, it is recommended to use the RIBCI to help the calculations of nurse staffing in obstetric rooming-in.

\section{FUNDING / ACKNOWLEDGMENT}

Fundo de Apoio ao Ensino, à Pesquisa e à Extensão da Universidade Estadual de Campinas (FAEPEX/UNICAMP).

\section{REFERENCES}

1. Fasoli DR, Haddock KS. Results of an Integrative Review of Patient Classification Systems. Ann Rev Nurs Res. 2010;28:295-316. doi: 10.1891/0739-6686.28.295

2. Perroca MG. Development and content validity of the new version of a patient classification instrument. Rev Latino-Am Enferm. 2011;10(1):58-66. doi: 10.1590/S0104-11692011000100009

3. Malloch K. Changing Tides: increasing evidence to embrace a patient classification system. Nurs Econ [Internet]. 2012 [cited 2019 Jul 13];30(6):356-8. Available from: https://www.nursingeconomics.net/necfiles/staffingUnleashed/su_ND12.pdf

4. Malloch K, Meisel M. Patient Classification Systems: State of the Science. Nurse Leader. 2013;11(6):35-37. doi: 10.1016/j.mnl.2013.09.008

5. Alghamdi MG. Nursing workload: a concept analysis. J Nurs Manag. 2016; 24(4):449-457. doi: 10.1111/jonm.12354

6. Conselho Federal de Enfermagem. Resolução n. 543/2017. Atualiza e estabelece parâmetros para o dimensionamento do quadro de profissionais de enfermagem nos serviços/locais em que são realizadas atividades de enfermagem. [Internet]. Brasília-DF: COFEN; 2017 [cited 2019 May 12]. Available from: http://www.cofen.gov.br/resolucao-cofen-5432017_51440.html.

7. Zenkner JRG, Miorin CFB, Cardoso LS, Ribeiro JP, Cezar-Vaz MR, Rocha LP. Rooming-in and Breastfeeding: Reviewing the impact on scientific production of nursing. Rev Pesqui Cuid Fundam. 2013;5(2):3808-18. doi: 10.9789/2175-5361.2013v5n2p3808

8. Campos FC, Soares FMM, Bezerra RA, Freitas SMFM, Holanda SM, Oliveira AS, et al. Exclusive breastfeeding: guidance in the process of communication between nursing staff and recent mothers. Int Arch Med. 2017;10(33). doi: 10.3823/2303

9. Dini AP, Guirardello EB. Pediatric patient classification system: improvement of an instrument. Rev Esc Enferm USP. 2014;48(5):76-92. doi: 10.1590/S0080-623420140000500003

10. Terwee CB, Prinsen CAC, Chiarotto A, Westerman MJ, Patrick DL, Alonso J, et al. COSMIN methodology for evaluating the content validity of patient-reported outcome measures: a Delphi study. Qual Life Res. 2018; 27(5):1159-70. doi: 10.1007/s11136-018-1829-0 
11. Reio Jr TG, Shuck B. Exploratory Factor Analysis: Implications for Theory, Research, and Practice. Adv Develop Human Resources. 2015;17(1):12-25. doi: 10.1177/1523422314559804 12.

12. Dauber BC, Cunha MLC. Postpartum women's level of comprehension of newborn care instructions at a rooming-in facility. Clin Biomed Res. 2017;37(3):193-197. doi: 10.4322/2357-9730.73453

13. Carvalho ACO, Saraiva ARB, Gonçalves GAA, Soares JRS, Pinto SL. Aleitamento materno: Promovendo o cuidar no alojamento conjunto. Rev Rene[Internet]. 2013[cited 2019 May 12];14(2):241-51. Available from: http://www.redalyc.org/pdf/3240/324027986003_2.pdf

14. Renfrew MJ, MdFadden A, Bastos MH, Campbell J, Channon AA, Cheung NF, et al. Midwifery and quality care: findings from a new evidenceinformed framework for maternal and newborn care. Lancet. 2014;384:1129-45. doi: 10.1016/S0140-6736(14)60789-3

15. Costa ALR, Araujo-Juniot E, Lima JWO, Costa FS. Fatores de risco materno associados à necessidade de unidade de terapia intensiva neonatal. Rev Bras Ginecol Obstet [Internet].2014[cited 2019 May 12]. 36(1). Available from: http://www.scielo.br/pdf/rbgo/v36n1/01007203-rbgo-36-01-00029.pdf

16. Escaron AL, Weir RC, Stanton P, Vangala S, Grogan T, Clarke RM. Testing na adapted modified delphi method: synthesizing multiple stakeholder ratings of health care service effectiveness. Health Educ Health Care. 2016.17(2):217-25. doi :10.1177/1524839915614308

17. Coluci MZO, Alexandre NMC, Milani D. Construção de instrumentos de medida na área da saúde. Cienc Saude Colet. .2015;20(3):925-36. doi: $10.1590 / 1413-81232015203.04332013$

18. Figueiredo Filho DB, Silva Jr JA. Visão além do alcance: uma introdução à análise factorial. Op Pública. 2010;16(1):160-85. doi: 10.1590/ S0104-62762010000100007

19. Tavakol M, Dennick R. Making sense of Cronbach's alpha. Int J Med Educ. 2011;2:53-55. doi: 10.5116/ijme.4dfb.8dfd

20. Olegário WKB, Fernandes LT, Medeiros CMR. Validation of ICNP Nursing Diagnoses for assistance to women during postpartum. Rev Eletrôn Enferm. 2015;17(3): doi: 10.5216/ree.v17i3.31502

21. Derya YA, Pasinlioglu T. The effect on nursing care based on Comfort Theory on Women's Postpartum Comfort Levels after caesarean sections. Int J Nurs Knowl. 2017; 28(3):138-44. doi: 10.1111/2047-3095.12122

22. Dulfe PAM, Aguiar RCB, Alves VH, Rodrigues DP. Nursing Care on admission and stay of the newborn in the accommodation set on intrahospital transfer. Rev Pesqui Cuid Fundam. 2015;7(2):2287-2297. doi: 10.9789/2175-5361.2015.v7i2.2287-2297

23. Miranda JOF, Camargo CL, Nascimento-Sobrinho CL, Portela DS, Monaghan A, Freitas KS, et al. Translation and adaptation of a pediatric early warning score. Rev Bras Enferm. 2016;69(5):888-896. doi:10.1590/0034-7167-2015-0096

24. Paliwoda M, New K, Bogossian F. Neonatal Early Warning Tools for recognizing and responding to clinical deterioration in neonates cared for in the maternity setting: A retrospective case-control study. Int J Nurs Stud. 2016; 61:125-35. doi: 10.1016/j.jnurstu.2016.06.006

25. Singh A, Guleria K, Vaid NB, Jain S. Evaluation of maternal early obstetric warning system (MEOWS chart) as a predictor of obstetric morbidity: a prospective observational study. Eur J Obstet Gynecol Reprod Biol. 2016; 207:11-17. doi: 10.1016/j.ejogrb.2016.09.014 